\title{
Trading Later Rewards for Current Pleasure: Pornography Consumption and Delay Discounting
}

\author{
Sesen Negash and Nicole Van Ness Sheppard \\ Couple and Family Therapy Program, Alliant International University, \\ San Diego, California \\ Nathaniel M. Lambert \\ Psychology Department, University of South Pacific, Suva, Fuji Islands \\ Frank D. Fincham \\ Family Institute, The Florida State University, Tallahassee, Florida
}

\begin{abstract}
Internet pornography is a multi-billion-dollar industry that has grown increasingly accessible. Delay discounting involves devaluing larger, later rewards in favor of smaller, more immediate rewards. The constant novelty and primacy of sexual stimuli as particularly strong natural rewards make Internet pornography a unique activator of the brain's reward system, thereby having implications for decision-making processes. Based on theoretical studies of evolutionary psychology and neuroeconomics, two studies tested the hypothesis that consuming Internet pornography would relate to higher rates of delay discounting. Study 1 used a longitudinal design. Participants completed a pornography use questionnaire and a delay discounting task at Time 1 and then again four weeks later. Participants reporting higher initial pornography use demonstrated a higher delay discounting rate at Time 2, controlling for initial delay discounting. Study 2 tested for causality with an experimental design. Participants were randomly assigned to abstain from either their favorite food or pornography for three weeks. Participants who abstained from pornography use demonstrated lower delay discounting than participants who abstained from their favorite food. The finding suggests that Internet pornography is a sexual reward that contributes to delay discounting differently than other natural rewards. Theoretical and clinical implications of these studies are highlighted.
\end{abstract}

Few barriers stand between one's desire and opportunity to experience an immediate sexual reward through Internet pornography. Sexual rewards are a primary short-term reason why many individuals view pornography (Boies, 2002), likely due to the strength of sex as a natural reward. Research is less clear, however, about the long-term consequences of pornography use. The current research was aimed at examining the impact of pornography use on individuals' tendencies to discount future outcomes in favor of immediate rewards, otherwise known as delay discounting. Could exposure to pornography refocus individual thought from a distant future to the wants of today? Could habitual sexual instant gratification have unique long-term consequences

Correspondence should be addressed to Sesen Negash, Couple and Family Therapy Program, 10455 Pomerado Road, Alliant International University, San Diego, CA 92131. E-mail: snegash@, alliant.edu on decision making that extend beyond temporary arousal?

Examining the link between pornography use and delay discounting is important for a number of reasons. One reason is the widespread popularity of pornography (Ropelato, 2007) and the rise in impulsive and compulsive pornography use (Wetterneck, Burgess, Short, Smith, \& Cervantes, 2012). Second, delay discounting has been linked to impulsivity (Fawcett, McNamara, \& Houston, 2012), erotic stimuli (Lawyer, 2008), and risky sexual behaviors (Johnson \& Bruner, 2012). Given that little research on delay discounting has focused on situational variables (Wilson \& Daly, 2004), such as pornography use, these findings call for research that examines the relationship between regular pornography consumption and decision-making processes. Accordingly, the current studies were conducted to examine the relationship between pornography use and delay discounting. 


\section{Internet Pornography Use}

Pornography is widely studied but inconsistently defined in the literature (Short, Black, Smith, Wetterneck, $\&$ Wells, 2012). For the purpose of the current research we broadly defined pornography as sexually explicit material, and Internet pornography as Web sites containing sexually graphic material. The use of Internet pornography has increased exponentially in the past few decades, due to what Cooper and Griffin-Shelley (2002) termed the "triple A engine": the increasing accessibility, anonymity, and affordability of the Internet. An article posted by the Huffington Post ("Porn Sites Get More Visitors," 2013) reported that $30 \%$ of all Internet data is related to pornography, and porn sites receive more visitors than Amazon, Netflix, and Twitter combined. The leading pornography site, Xvideos, receives an estimated 4.4 million viewers per month (Anthony, 2012). Carroll and colleagues (2008) examined emerging adults' pornography use with a geographically representative sample of 813 undergraduate students (aged 18 to 26; 500 women and 313 men; mean age $20 ; 70 \%$ Caucasian) recruited from various universities. Their findings revealed that, among young adults, $87 \%$ of men and $31 \%$ of women reported consuming pornography to some degree, and $20 \%$ of the men reported viewing it daily or every other day. Wright, Tokunaga, and Bae (2014b) showed a more conservative estimate. In their cross-sectional, nationally representative sample of 7,000 individuals, between 2000-2012 an estimated $27 \%$ of Americans aged 18 to 89 reported viewing pornography at least once a year.

The speed and availability that the Internet affords allows users to quickly and repeatedly expose themselves to novelty. Many researchers have studied the role of novelty in increasing sexual motivation and behavior, commonly referred to as the Coolidge effect (Dewsbury, 1981; Wilson, Kuehn, \& Beach, 1963). This phenomenon occurs because surges of dopamine, implicated in motivation and reward seeking, occur in response to novel sexual stimuli (Kleitz-Nelson, Dominguez, Cornil, \& Ball, 2010; Krebs, Heipertz, Schuetze, \& Duzel, 2011).

\section{Pornography and Dopaminergic Reward System Activation}

Dopamine plays a key role in motivation, goaloriented and appetitive behaviors, and learning, as well as impulse control and self-regulation (Arias-Carrión, Stamelou, Murillo-Rodríguez, Menéndez-González, \& Pöppel, 2010; Arias-Carrión et al., 2014; Cetin, Freudenberg, Füchtemeier, \& Koch, 2004; Phillips, Vacca, \& Ahn, 2008). Dopamine has been referred to as the "pleasure neurotransmitter" because it plays a large role in the processes of the so-called reward center of the brain (Arias-Carrión et al., 2014, p. 3) and is involved in reward-seeking behaviors (Cetin et al., 2004). Of further interest are findings suggesting that dopamine influences the evaluation of both the anticipated value of rewards and when they are expected (immediate or future; Arias-Carrión et al., 2010; Caplin $\&$ Dean, 2008). According to the reward prediction error hypothesis, dopamine is released only for unexpected rewards, which is relevant for current purposes due to the constant novelty inherent in Internet pornography (for further discussion of the reward prediction error hypothesis, see Caplin \& Dean, 2008; Colombo, 2014). Habitual reward seeking has implications for arousability, decision making, and impulsivity, a relevant component of which is delay discounting.

\section{Delay Discounting}

Delay discounting is a devaluing of future outcomes (Rachlin \& Green, 1972) and is an aspect of impulsivity (Winstanley, 2010). In delay discounting, the individual shows preference for smaller and sooner rewards in lieu of the prospect of obtaining larger but later rewards (Mischel \& Underwood, 1974; Smits, Stein, Johnson, Odum, \& Madden, 2013). An example of delay discounting would be eating a piece of cake now, a small reward, instead of opting for larger but delayed rewards, such as wanting to maintain healthy weight and avoid weight-related illnesses over the long term. Fawcett and colleagues (2012) outlined literature characterizing the act of delay discounting as "impatient, impulsive, shortsighted, or lacking in self-control" (p. 128). These characteristics are typically viewed as negative in our society and are also associated with deviant behaviors (Buzzell, Foss, \& Middleton, 2006) and addictions (MacKillop, 2013). Delay discounting is commonly linked to impulsive decision making (Crean, de Wit, \& Richards, 2000), obesity (Davis, Patte, Curtis, \& Reid, 2010), substance abuse (e.g., Romer, Duckworth, Sznitman, \& Park, 2010), excessive gambling (e.g., Dixon, Jacobs, \& Sanders, 2006), risky sexual behavior (Chesson et al., 2006), and Internet addiction (e.g., Saville, Gisbert, Kopp, \& Telesco, 2010).

\section{Theoretical Framework}

Given the relationship between delay discounting and both impulsivity and risk taking (Fawcett et al., 2012; Johnson \& Bruner, 2012), it is important to consider delay discounting in terms of both its development and its consequences. Delay discounting is associated with limited capacity for delayed gratification, an ability that starts with early childhood learning, and shows the most change in midadolescence due to brain development and neural plasticity (Steinberg et al., 2009). One explanation for delay discounting is the competing neurobehavioral decision systems theory (Bechara, 2005; Jentsch \& Taylor, 1999). In this theory, conflicted 
choices of delay discounting are attributed to an imbalance in the development and regulation of two brain systems: the impulsive limbic and paralimbic systems, which value immediate rewards; and the prefrontal cortical region, responsible for reflective and executive functioning, which can allow for delayed gratification (Bickel et al., 2007). Van den Bergh, Dewitte, and Warlop (2008) referred to these as "hot" and "cool" processes, respectively (p. 95). Given that the impulsive system (limbic and paralimbic brain regions) is evolutionarily older than the executive system (prefrontal cortices), conflicts in motivation and decision making about delayed rewards, such as food or sex, can be explained by relative strengths and weaknesses in these two systems due to developmental or individual differences (Koffarnus, Jarmolowicz, Mueller, \& Bickel, 2013).

Using a sample of 1,042 adolescents and young adults, Chesson and colleagues (2006) found that higher discounting tendencies were associated with more risky sexual behaviors and tended to decrease with age (the latter finding is also supported by Van den Bergh et al., 2008 and Hayaki, Anderson, \& Stein, 2006). Van den Bergh and colleagues (2008) highlighted the general reward circuitry as it influences reward sensitivity and delay discounting. They found that those with reward sensitivity showed impatience and discounting in multiple domains after exposure to sexual stimuli. Given these developmental considerations, it is important to consider whether individual differences in biological processes explain differences in tendencies toward impulsivity, pornography consumption, and delay discounting - or if there are other explanatory factors.

Garcia and colleagues (2010) assessed whether genetic variations in dopaminergic receptivity were responsible for variations in sexual promiscuity and delay discounting. Their findings showed that individuals with genetically lower dopamine sensitivity demonstrated higher rates of impulsivity, disinhibition, sexual promiscuity, risk taking, and other rewardseeking behaviors, but that the genetic differences did not predict differences in delay discounting. In other words, biological predisposition may influence impulsivity and reward seeking; however, it does not exclusively explain delay discounting tendencies.

There have been several other theoretical analyses of delay discounting, including crime theory and self-control theory (Buzzell et al., 2006); personality and psychological theories (Malesza \& Ostaszewski, 2013); economics (Bickel et al., 2010); neuroeconomics (e.g., Bickel et al., 2007); evolutionary functional model (Fawcett et al., 2012); and neural and neurochemical mechanisms (Winstanley, 2010). Pornography use is controversial, with varying social connotations, such that using crime theory or personality explanations to link delay discounting with pornography use may imply a value judgment and be more observational than explanatory.
Therefore, the objective and explanatory nature of neuroeconomics and evolutionary psychology were used to provide a framework for the current research. Extant research on reward system mechanisms in decision making was also used to examine consequences of pornography consumption on behavior.

Economic psychologists have proposed that cuebased or visceral stimuli (those associated with instincts such as fear, hunger, pain, and sexual drive) elicit unique responses that favor immediate gratification (O'Malley, Davies, \& Cline, 2010). O'Malley and colleagues (2010) specifically tested the common assumption that delay discounting follows an exponential model, which is a constant discount rate over time. They presented male subjects with images of sexual and nonsexual, nonvisceral stimuli (e.g., Tupperware) as well as a short- and long-term discounting task. O'Malley et al. found that participants were more likely to delay discount in response to sexual stimuli than to nonsexual stimuli and to discount more for short-term than long-term rewards. Their findings indicate a hyperbolic function of delay discounting, such that cue-based sexual stimuli in particular increase the need for instant gratification in the short term but not the long term. Noting inconsistency with linear (and more predictable) models led O'Malley and colleagues (2010) to conclude that cue-based stimuli elicit emotional responses that make human behavior less consistent than with nonemotional situations. This conclusion is relevant in that pornography is a sexual cue-based stimulus. The conclusion is also supported by research showing that cue-based stimuli activate the dopamine system, rendering people more susceptible to seeking instant gratification (AriasCarrión et al., 2014; O’Malley et al., 2010).

\section{Weighing Rewards to Make Decisions}

The language of rewards comes from the study of neuroeconomics, or the study of brain activity associated with behavior and decision making (Lungu \& Puscasu, 2013). Rewards are objects or goals that individuals dedicate time and energy to seek and can be natural, chemical, tangible, or social (Arias-Carrión et al., 2014). In the current studies, we considered the natural rewards of sex and food based on Wise's (1980) hedonia hypothesis. The hedonia hypothesis refers to "the hedonic messages we experience as pleasure, euphoria or "yumminess" (p. 94) in response to rewards. Natural rewards are considered primary because they are key for survival; more abstract rewards, like money, have to be learned secondarily (Arias-Carrión et al., 2014). Other delay discounting studies have focused on chemical rewards, like drugs or alcohol (Stein \& Madden, 2013) or tangible rewards, such as money (Malesza \& Ostaszewski, 2013). Although exposure to chemical rewards leads to greater long-term changes in the brain than natural rewards, 
the natural reward of sex leads to long-term changes in plasticity similar to those elicited by the chemical reward of cocaine (Chen et al., 2008; Hilton, 2013).

Fawcett and colleagues (2012) utilized a normative approach (i.e., a model of decision making that accounts for the importance of a particular decision and situation to determine the most effective decision-making process) to understand the evolutionary basis of delay discounting in motivation and decision making. In economic terms, choosing a smaller reward now instead of a larger reward later makes little sense, especially when the later reward is guaranteed. In evolutionary terms, however, waiting for delayed rewards is risky. The risks include energy expenditure from waiting, the possibility of the reward becoming unavailable, predator threat, and other possible threats or opportunity costs associated with forgoing immediately available rewards that are important for survival, such as food or sex (see Fawcett et al., 2012, for further explanation of functional models of delay discounting). The survival advantage of delay discounting for animals and humans, therefore, is to "get while the getting is good." There are also other factors to consider, such as perceptions about the current situation, the types of choices expected, flexibility, and awareness of the expected or continued availability of the reward, that further contribute to tendencies to delay discount (Fawcett at al., 2012). Together these findings support the idea that while developmental and biological predisposition may play a major role in one's discounting and impulsivity tendencies, both behavior and the nature of stimuli and rewards also contribute to the development of such tendencies.

To summarize, given the considerations of motivation, decision making, and the neural substrates of reward, the current studies examined the link between pornography use and delay discounting from the perspectives of neuroeconomics and evolutionary psychology. Collectively, these findings highlight what we know about the neural and psychological mechanisms of how and why delay discounting may occur, as well as possible effects and outcomes. Little is known, however, about how lifestyle and behavioral choices, such as consuming Internet pornography, may influence delay discounting.

\section{Pornography and Delay Discounting}

We proposed that pornography consumption would increase impulsivity, as manifested by delay discounting, for three reasons. The first is that sexual urges can be extremely powerful and, not surprisingly, sexual behavior has been related to impulsivity in prior research. For example, sexual arousal is related to higher levels of impulsive decision making (Hayaki et al., 2006; Hoyle, Fejfar, \& Miller, 2000), which is directly linked to delay discounting. Additional findings from experimental studies by Wilson and Daly (2004), Van den Bergh and colleagues (2008), and O'Malley and colleagues (2010) showed that individuals exposed to sexual stimuli (e.g., images of sexually attractive people) displayed a higher rate of delay discounting than those who were exposed to nonerotic stimuli (e.g., images of Tupperware; O'Malley et al., 2010). Conclusions from these studies support the link between delay discounting and the sexual stimulus of pornography.

The second reason we propose a link between pornography consumption and delay discounting is because we believe that pornography consumption serves as a replacement for sexual encounters with real partners. Such replacement can be an attractive substitute for human contact for several reasons. Some people view pornography as a form of recreation that is void of responsibility or obligation and as a way to protect themselves from sexually transmitted infections (STIs) (Quinn \& Forsyth, 2005). The user may experience personal fulfillment (Quinn \& Forsyth, 2005) or the feeling of being transported into a fantasy experience (Philaretou, Mahfouz, \& Allen, 2005). Unlike real-life sexual encounters, pornography provides convenience, anonymity, and less risk of embarrassment (Philaretou et al., 2005). The primacy of sexual rewards and the nature of the dopaminergic reward mechanism explains why repeat pornography users quickly become conditioned by the instant sexual gratification, which can result in habitual use (Arias-Carrión et al., 2014; Wilson, 2014). As opposed to developing and nurturing a relationship and then waiting for a partner to be sexually responsive, some people may use pornography for a more immediate shortcut to sexual reward.

The third reason for our hypothesis is that pornography is largely Internet based. The constant accessibility and novelty of Internet pornography triggers repeated reward activation, which can lead to habituation over time (Arias-Carrión et al., 2014). Researchers linking neuroscience and pornography have applied fundamental knowledge about how the processes of learning, habituation, motivation, and appetitive drives lead individuals toward natural reinforcers (e.g., Hilton, 2013; Wilson, 2014). Such accounts have outlined a process whereby constant novelty and instant gratification inherent in Internet pornography use spark repeated dopamine surges. Over time these surges serve both to sensitize the brain to the highly rewarding stimulus (pornography) and to desensitize the natural reward system response by way of habituation. This pattern may also quickly condition a reward-seeking habit.

Using three experimental studies, Ramanathan and Menon (2006) demonstrated how reward sensitivity and chronic pleasure seeking are functions of impulsivity. They indicated that natural reward-based contextual cues activate pleasure-seeking (hedonic) goals, which can diminish self-control and increase impulsivity, even among people otherwise skilled at self-control. Similarly, Van den 
Bergh and colleagues (2008) also implicated the dopaminergic reward system in their framework for examining sexual cues and discounting. Given that studies of both pornography use and delay discounting share the common factors of impulsivity, salience of sexual stimuli, and reward seeking, we proposed that Internet pornography use will produce increasing rates of delay discounting. While dopaminergic processes are not examined in the current studies, we believe the dopamine system is the underlying mechanism that would best provide a rationale for the results of these studies.

\section{Purpose of Current Studies}

Several researchers have made inferences about the effects of sexual behavior on impulsivity (Chesson et al., 2006; Hayaki et al., 2006) or have found that erotic stimuli were related to a higher rate of delay discounting using cross-sectional (Lawyer, 2008) or experimental (Van den Bergh et al., 2008; Wilson \& Daly, 2004) methods. Some researchers (e.g., Chesson et al., 2006; Hayaki et al., 2006) have examined behavior as a result of impulsivity or the tendency to delay discount. Others (e.g., O'Malley et al., 2010; Wilson \& Daly, 2004; Van den Bergh et al., 2008) have presented sexual stimuli in the laboratory setting immediately prior to implementing a delay discounting task. Conversely, the current studies took a different approach by examining delay discounting as a result of the specific sexual stimulus of voluntary porn use that was outside of a controlled laboratory environment. The current investigation is the first to examine this relationship longitudinally and to determine whether the causal effect of sexual stimuli on delay discounting would extend beyond momentary arousal. Specifically, the studies examined the accumulated effect of sexual stimuli on delay discounting by assessing both naturally occurring (Study 1) and altered (Study 2) pornography consumption over time on delay discounting while participants were presumably not aroused.

\section{Study 1}

Given that prior researchers have examined the link between sexual behavior and delay discounting using cross-sectional designs (e.g., Lawyer, 2008; Lawyer, Williams, Prihodova, Rollins, \& Lester, 2010), we provided information about the direction of the relationship between pornography consumption and delay discounting using a longitudinal design. Although causal inferences may not be drawn, the longitudinal nature of the study can be used to examine the temporal sequencing of the association between pornography and delay discounting (e.g., Wright, Tokunaga, \& Bae, 2014a).
We hypothesized that the frequency with which participants consumed pornography at Time 1 would predict Time 2 delay discounting, even when controlling for initial levels of delay discounting.

\section{Method}

\section{Participants}

Participants were 123 (32 men and 91 women) students from a Southeastern university who agreed to participate in an ongoing online survey in exchange for course credit. Measures for the study came from a larger data collection used to examine various young adult behaviors. Participants ranged in age from 18 to 27 with a median age of 20 . In this sample $72 \%$ were White, 13\% were African American, 7\% were Latino, and the remainder indicated mixed race, Asian, or other.

\section{Measures and Procedure}

Prior approval was obtained from the institutional review board for all procedures. Students were asked to participate in a study that examined individual and relationship factors among college students. Those who agreed to participate accessed the online survey via a secure URL link sent to their private school e-mail accounts and were given one week to complete the survey. Before beginning the survey, students completed an electronic informed consent form that highlighted the nature of the personal questions in the study as well as the terms and conditions of their participation. The measures were completed at the beginning of the academic semester and then again four weeks later (using the same procedures). Participants who did not begin or complete the initial survey (i.e., those who missed most of the control questions) were not provided access to the second survey four weeks later.

Pornography use. Similar to other studies (e.g., Wright, 2012, 2013; Wright et al., 2014a), pornography use was measured using a single item: "Approximately how many times in the past 30 days have you viewed a pornographic website?" Choices ranged from Never to Several times a day.

Delay discounting. Hypothetical or real monetary outcomes are commonly used for delay discounting tasks (e.g., Johnson \& Bruner, 2012). Using a series of forced-choice options, participants answered a series of questions about receiving real monetary rewards. The questions and procedure were adapted from previous studies used to test individuals' delay discounting choices (e.g., Green, Myerson, \& Ostaszewski, 1999; Kirby \& Maraković, 1996). Participants were told that in exchange for their participation they would be eligible 
for prize money that would be given out through a series of raffle ticket drawings (e.g., "Your answers to the following questions will have a direct effect on when and how many raffle tickets you receive for each drawing, so think carefully as you answer the following questions"). Then participants completed six items that pitted present gain against future gain. For example, participants were asked: "Would you prefer 1 ticket today for our upcoming drawing or 4 in 40 days for our drawing in 40 days?" The number of immediately available tickets ranged from one to four, whereas the number of delayed tickets ranged from two to six. Delays ranged from 15 days to 180 days. The value of a participant's hyperbolic discounting parameter $(k)$ was inferred from the point at which he or she shifted from preferring the larger, later reward, to preferring the smaller, sooner reward. The frequency distribution of $k$ was nonnormal (Time 1: skewness $=1.28$, 1.28 , kurtosis $=.62$; Time 2: skewness $=1.05$, kurtosis $=$ -.10 ), so values were transformed using a natural $\log$ transformation (Time 1: $M=-4.54, S D=1.70$; Time 2: $M=-4.30, S D=1.71)$.

\section{Results}

To investigate whether self-reported use of pornography at Time 1 predicted $k$ at Time 2, we ran a linear regression model in which $k$ values at Time 2 were regressed on gender and values of $k$ at Time 1 and on pornography use. The overall model was statistically significant, $F(3,120)=10.51, p<.001$, adjusted $R^{2}=.19$. In this model, despite controlling for gender and $k$ at Time 1 , pornography use at Time 1 significantly predicted Time $2 k(\beta=.21, p<.05)$, such that participants who reported viewing more pornography initially demonstrated higher discounting of future rewards at Time 2. Descriptive statistics by gender are presented in Table 1 .

\section{Discussion}

The more pornography that participants consumed, the more they saw the future rewards as worth less than the immediate rewards, even though the future rewards were objectively worth more. These results indicate that continued exposure to the immediate gratification of pornography is related to higher delay discounting over time. These results parallel Ramanathan and Menon's (2006) finding that chronic pleasure goal seeking increased impulsivity. It is also consistent with both evolutionary considerations and the competing neurobehavioral decision systems theory for impulsive decision making for natural reward seeking (Bechara, 2005; Bickel et al., 2007; Jentsch \& Taylor, 1999). The direction of effects and the causal nature of the relationship in our results, however, are still in question. Hence, we used an experimental design in Study 2 to replicate and extend these effects.

\section{Study 2}

Although Study 1 provides some evidence for direction of effects, whether pornography consumption causes higher delay discounting rates can be determined only through an experimental design. Rather than randomly assign individuals who did not consume pornography to begin consuming it, a strategy forgone for ethical reasons, we randomly assigned individuals currently viewing pornography to refrain from doing so. We presumed that requesting a regular pornography user to abstain from pornography for three weeks would require a large amount of self-control. Given that prior research demonstrated a connection between sexual stimuli in particular and delay discounting (e.g., Lawyer, 2008; Lawyer et al., 2010; Van den Bergh et al., 2008; Wilson \& Daly, 2004), we did not compare this treatment to a no-treatment condition. Any difference found in such a comparison might reflect the fact that simply exercising self-control in one domain (sexual behavior) affected self-control in another domain (delay discounting).

In contrast, we wanted to test specifically whether exercising the self-control within the sexual domain (abstaining from pornography consumption) would have a greater effect on delay discounting than would

Table 1. Descriptive Information by Gender

\begin{tabular}{|c|c|c|c|c|c|c|c|c|}
\hline \multirow[b]{2}{*}{ Variable } & \multicolumn{4}{|c|}{ Men } & \multicolumn{4}{|c|}{ Women } \\
\hline & $N$ & Range & $M$ & $S D$ & $N$ & Range & $M$ & $S D$ \\
\hline \multicolumn{9}{|l|}{ Study 1} \\
\hline Pornography use (Time 1) & 32 & $1-7$ & 2.41 & 1.24 & 91 & $1-7$ & 1.21 & 0.55 \\
\hline Delay discounting (Time 1) & 32 & $6-12$ & 9.03 & 2.09 & 91 & $6-12$ & 9.27 & 1.98 \\
\hline Delay discounting (Time 2) & 32 & $6-12$ & 8.91 & 2.31 & 91 & $6-12$ & 9.23 & 2.02 \\
\hline \multicolumn{9}{|l|}{ Study 2} \\
\hline Pornography use (Time 1) & 24 & $1-7$ & 3.79 & 1.1 & 13 & $1-7$ & 4.08 & 1.44 \\
\hline Pornography use (Time 2) & 22 & $1-7$ & 2.64 & 1.73 & 12 & $1-7$ & 2.58 & 1.38 \\
\hline Delay discounting & 24 & $1-2$ & 1.63 & 0.45 & 13 & $1-2$ & 1.69 & 0.48 \\
\hline
\end{tabular}


exercising self-control in another domain (abstaining from a nonsexual appetite). Thus, half of the participants abstained from pornography and half of the participants abstained from their favorite food for three weeks. Given that sex and food are both natural rewards that operate similarly in the brain's reward circuitry (Agustín-Pavón, Martínez-Ricós, Martínez-García, \& Lanuza, 2008), we selected food as the most comparable reinforcer from which to abstain. We hypothesized that participants who continued to consume pornography for three weeks (no exercise of sexual self-control) would report a higher delay discounting rate than those who abstained from pornography (exercise of sexual selfcontrol) during that time period.

\section{Method}

\section{Participants}

Participants attended a Southeastern university and were offered an opportunity to participate in the study in exchange for extra credit. In all, 274 participants reported on how frequently they consumed pornography. Of these, 57 reported that they viewed pornography More than once per month and were invited to participate in the current study. Of those 57,37 students (24 men and 13 women) agreed to participate in exchange for additional extra credit. Participants ranged in age from 18 to 28 with a median age of 19. In this sample, $76 \%$ were White, $16 \%$ were African American, $5 \%$ were Latino, and the remainder indicated mixed race, Asian, or other.

\section{Measures and Procedure}

Participants were initially contacted by e-mail to complete an online survey in exchange for extra credit. As part of their participation students were required to complete various measures used in this study as well as in unrelated studies. Students completed an electronic informed consent form that highlighted the nature of the personal questions in the study as well as the terms and conditions of their participation. Those who responded that they viewed pornography were invited via e-mail to participate in the current experiment a few weeks later. Participants who agreed to complete the study were directed to a secure online portal Web site and were randomly assigned to either abstain from pornography or to abstain from eating their favorite food for a three-week period. All participants were instructed that this study was about self-control and that they were randomly chosen to abstain from their assigned activity. Participants were unaware that they were picked for the study based on their self-reported pornography use. Participants who had any questions about the study were also instructed to contact the researchers via e-mail at any time.
Pornography use. Pornography use was assessed by asking participants: "Approximately how many times in the past 30 days have you viewed a pornographic website?" Choices ranged from Never to Several times a day.

Abstain from pornography condition. The 16 participants randomly assigned to the experimental condition were given the following instructions: "You have been assigned to abstain from viewing porn, including all websites, magazines, videos, etc. that show nudity or sexually explicit materials of any kind for the next three weeks. We hope that you will be diligent at refraining from porn for this short period of time, but also, please be honest and let us know if you did view porn as such honesty will not count against your receiving extra credit."

As part of the assignment participants marked a daily calendar for each day they abstained from pornography. In addition, at the start of each week they were required to write a paragraph about their success (or lack thereof) in abstaining. They also wrote a plan for how they would handle their desire to view pornography (e.g., to distract themselves).

Food abstinence/continued pornography consumption condition. A total of 21 participants were randomly assigned to the favorite food abstinence/continued pornography consumption condition. The objective of this control condition was twofold: first, to not disrupt the participants' regular consumption of pornography; and second, to ensure that simply practicing self-control was not driving the results. Participants in this condition were given the following instructions: "You have been assigned to abstain from eating your favorite food or treat for the next three weeks. We hope that you will be diligent at refraining from your favorite food or treat for this short period of time, but also, please be honest and let us know if you did eat your favorite food as such honesty will not count against your receiving extra credit." Participants in this condition also marked a daily calendar for each day they abstained from their favorite food. In addition, at the beginning of each week they were required to write a paragraph reporting about their success (or lack thereof) in abstaining from their favorite food. They also wrote about their plan to handle their desire to eat their favorite food when they had a desire to eat it.

Delay discounting. The delay discounting task in Study 2 was simpler than the one used in Study 1. Participants answered a series of questions about receiving real monetary rewards. At the end of the three weeks, participants were instructed that they were going to have a chance to receive raffle tickets for a series of raffle drawings for a few hundred dollars in cash prizes 
as a reward for participating in the study. Three questions were asked: "Would you prefer to enter all your electronic raffle tickets today for our upcoming drawing or would you prefer to have all those tickets plus 10 entered in two weeks for our drawing in two weeks (or plus 20 tickets in four weeks, or plus 30 in six weeks)? Because participants answered only three questions, and they made this decision without knowing exactly how many tickets they would earn, the percentage of times that the larger, later amount was chosen over the smaller, sooner reward was calculated $(M=.65$, $S D=.43)$ rather than $k$. In other words, the index of delay discounting was the proportion of questions for which a participant chose the delayed option.

\section{Results and Discussion}

\section{Procedure Check}

Findings showed no difference in baseline pornography consumption prior to the experiment between participants in the abstain from pornography condition $(M=3.81, S D=1.11)$ and those in the comparison condition $(M=3.95, S D=1.32), t(35)=-.341, p=.74$. To ensure that participants in the abstain from pornography condition actually abstained, we again asked them how many times in the past month they had viewed pornography. Participants in the abstain from pornography condition viewed significantly less pornography $(M=1.53, S D=.83)$ than those in the comparison condition $(M=3.47, S D=1.54), F(1,32)=19.25$, $p<.001, \eta_{p}^{2}=.38$. Thus, the procedure had the intended effect.

\section{Effect of Pornography on Delay Discounting}

A one-way analysis of variance (ANOVA) was used to investigate whether continued use of pornography affected delay discounting. As predicted, participants who exerted self-control over their desire to consume pornography chose a higher percentage of larger, later rewards $(M=.81, S D=.37)$ compared to participants who exerted self-control over their food consumption but continued consuming pornography $(M=.51, S D=$ $.47), F(1,35)=4.11, p=.05, \eta_{p}^{2}=.11$, controlling for gender (see Table 2).

Thus, building on the longitudinal findings of Study 1, we demonstrated that continued pornography

Table 2. ANOVA: Delay Discounting After Abstaining From Porn or Favorite Food

\begin{tabular}{lcccc}
\hline Source & $\boldsymbol{d f}$ & $\boldsymbol{F}$ & $\boldsymbol{p}$ & Partial $\boldsymbol{\eta}^{\mathbf{2}}$ \\
\hline $\begin{array}{l}\text { Between groups } \\
\text { Condition }\end{array}$ & 1.00 & 4.11 & $.05^{*}$ & 0.11 \\
\begin{tabular}{l} 
Error \\
\hline
\end{tabular} & 35 & & & \\
\hline
\end{tabular}

${ }^{*} p=0.05$. consumption was causally related to a higher rate of delay discounting. Exercising self-control in the sexual domain had a stronger effect on delay discounting than exercising self-control over another rewarding physical appetite (e.g., eating one's favorite food).

\section{General Discussion}

In the current studies, we tested our hypothesis that using pornography would predict the rate of delay discounting. In Study 1 we utilized a longitudinal design to test the effect of pornography use on delay discounting over time. Participants completed a questionnaire about their pornography use and a delay discounting task at Time 1 and then again four weeks later at Time 2. We found that participants who reported higher initial pornography use demonstrated higher delay discounting rates at Time 2, controlling for initial delay discounting.

In Study 2 we used an experimental design to provide causal evidence regarding pornography consumption and delay discounting among participants who reported regular use of pornography. By random assignment, participants practiced self-control with a natural reward, within either the sexual domain (by not consuming pornography for three weeks) or the food domain (by not consuming their favorite food for three weeks but still consuming pornography). As predicted, participants who refrained from viewing pornography chose more larger, later rewards compared to participants who ceased eating their favorite food but continued viewing pornography. In light of prior research that links sexual stimuli and delay discounting (e.g., Lawyer, 2008; Lawyer et al., 2010; Van den Bergh et al., 2008; Wilson \& Daly, 2004), these findings confirm our hypothesis that exercising self-control in the sexual domain has a greater effect on reducing delay discounting than exercising self-control in another domain (e.g., food abstinence).

The results of the current studies suggest an accumulation effect of regularly obtaining immediate reward through pornography, which predicted a higher rate of delay discounting over time. The longitudinal nature of both of the studies in this article indicates that the effects of pornography use on delay discounting can extend even beyond the temporary state of arousal. These results are also consistent with research indicating long-term effects of pornography use on the brain's dopaminergic reward system (e.g., Hilton, 2013; Romano, Osborne, Truzoli, \& Reed, 2013; Volkow et al., 2010; Wilson, 2014).

The results have important theoretical implications because they suggest that regular self-control in some domains (e.g., sexual) might be more powerful than self-control exercised in other domains (e.g., food) in strengthening self-control. Our results also bolster findings that differences in delay discounting are largely due 
to behavior rather than genetic predispositions (e.g., Garcia et al., 2010; Hong et al., 2013.

The main findings are also important at an applied level. In particular, the generalization of self-control intervention effects, or even their efficacy, may depend on the domain in which interventions are implemented. In light of the competing neurobehavioral decision systems theory, exercises aimed at strengthening the executive brain region functioning that allows for delayed gratification could also decrease delay discounting tendencies (Koffarnus et al., 2013).

\section{Limitations and Future Directions}

This study is not without its limitations. Research shows that, relative to adults, young people are less oriented toward the future (Steinberg et al., 2009). Consistent with this, individuals discount the value of delayed rewards less as they get older (Green et al., 1999). Given the impact of age on future orientation and discounting rates, the college sample in this study may limit the generalizability of the findings to the general population. Future studies should examine the moderating effect of age on pornography consumption and delay discounting. There are also the additional limitations of self-report measures and concerns about social desirability. Despite its popularity, pornography use remains stigmatized and has often been characterized as deviant (Buzzell et al., 2006). Thus, it is possible that participants may have underreported their pornography use. After a three-week period participants may have also misrepresented or mistakenly reported their pornography use.

Further investigation is needed to examine whether delay discounting mediates the relationship between casual pornography use and addictive or compulsive use, as well as the implications of this on romantic relationships. We recommend this study be replicated using a sample of compulsive/addictive users to see if the effect is similar, if not stronger, based on the positive feedback loop that more use leads to patterned seeking, habituation, and craving. Further research is also needed that examines the individual and relational factors contributing to differences between problematic and nonproblematic Internet pornography use.

Pornography use engenders different responses in users (Allen et al., 2007). Thus, it is important that researchers in future studies account for individual variations in response to pornography use when examining the link between pornography use and delay discounting. For example, the complexities of both reward processes and excitatory and inhibitory mechanisms (Janssen, Vorst, Finn, \& Bancroft, 2002) call for research that closely examines how sexual excitation and inhibition during pornography use affect individuals' subsequent delay discounting behaviors. Propensity for sexual excitation refers to the likelihood of an individual becoming sexually aroused in response to sexual or nonsexual stimuli. Propensity for sexual inhibition refers to the likelihood of reduced sexual response due to the threat of performance failure or of negative consequences. Both are mechanisms of the central nervous system that independently influence sexual response and help explain how sexual arousal and desire vary between and within persons (Carpenter, Janssen, Graham, Vorst, \& Wicherts, 2008; Janssen \& Bancroft, 2007). The dual control model of sexual excitation and inhibition may also explain why individuals experience disparate responses when viewing pornography. We predict that, compared to users who experience sexual inhibition from pornography, users who experience sexual excitation are more likely to become aroused by it and use it more. As a consequence, that may increase their likelihood of engaging in delay discounting. However, further analyses are needed to confirm this assumption.

In addition, findings from Koukounas and McCabe (2001) showed that attentional and affective processes influenced individuals' physiological and subjective sexual response to pornography. Consistent with this, Oliveira and colleagues (2014) found that both cognitive and affective processes influenced excitatory or inhibitory sexual responses to pornography. These findings, combined with findings from the current article, call for future studies that examine how affective and cognitive factors experienced during pornography use impact delay discounting.

Last, the mediating effects of delay discounting on the link between pornography use and certain sexual risk behaviors could use closer examination. For instance, research shows that risky sexual behaviors (e.g., poor condom use, infidelity, hooking up) are linked to pornography use (Braithwaite, Coulson, Keddington, \& Fincham, 2015; Wright 2013; Wright \& Randall, 2012; Wright et al., 2014a) as well as delay discounting (e.g., Chesson et al., 2006; Howard, 2014; Johnson \& Bruner, 2012). The aforementioned associations, combined with recommendations by researchers to assess for psychological processes that mediate the link between pornography and sexual risk taking (i.e., Wright \& Randall, 2012), call for future studies that examine whether delay discounting mediates the relationship between pornography consumption and risky sexual behaviors.

\section{Clinical Implications}

There are practical and clinical implications of these findings for both researchers and therapists. Research shows that pornography use contributes to relational as well as individual distress (Lambert, Negash, Stillman, Olmstead, \& Fincham, 2012). This finding, in combination with the link between discounting behaviors used to make monetary decisions and the processes used to make intertemporal choices in romantic 
relationships (Tayler, Arantes, \& Grace, 2009), suggest that therapists should carefully assess for both pornography use and delay discounting behaviors in couples therapy. For example, therapists may treat the pornography use directly to help clients change their discounting behavior, which may help them improve their impulse control and subsequently their ability to manage their presenting problem(s).

Compulsivity and addiction. Compulsive Internet pornography use is on the rise (Wetterneck et al., 2012). Furthermore, Cooper, Delmonico, and Burg (2000) estimated that $17 \%$ of pornography users in the United States met the criteria for sexual compulsivity. Wetterneck and colleagues (2012) defined compulsivity as a "compelling, nagging, or distracting feeling that one must engage in a certain behavior" (p. 4). Pornography use in itself may be a harmless activity (e.g., Wright \& Randall, 2012) but, given what we know about the reward system and the primacy of sex as a natural reward and visceral stimulus, it also has the potential to become compulsive or addictive.

With regard to the current sample of college students (median ages of 19 and 20), it is important to be aware that, biologically, adolescence extends to approximately age 25 (Kaplan, 2004). Adolescents show more reward sensitivity (Doremus-Fitzwater, Varlinskaya, \& Spear, 2010) and less aversion to overconsumption, making them more susceptible to addiction (Schramm-Sapyta, Walker, Caster, Levin, \& Kuhn, 2009). Jentsch and colleagues (2014) highlighted how addictions are related to impulsivity, which can also cause difficulties with interpersonal relationships (Watkins, Maldonado, \& DeLillo, 2014). We do think it is important to reiterate that although our subjects did not report being addictive or compulsive users, the underlying reward and learning mechanisms that often lead to addiction still apply. Our study is the first we know of to show alterations in decision-making processes from use that is not compulsive or addictive. Because of the addiction potential and the mutually reinforcing components of the reward system and impulsive behavior, we suggest our findings indicate an early warning sign that use could easily lead to abuse and thus the related consequences.

\section{Conclusion}

The current research is the first to test the link between pornography consumption and delay discounting using both longitudinal and experimental methods. Internet pornography is a sexual reward that contributes to delay discounting differently than other natural rewards do, even when use is not compulsive or addictive. This research makes an important contribution, demonstrating that the effect goes beyond temporary arousal. Pornography consumption may provide immediate sexual gratification but can have implications that transcend and affect other domains of a person's life, especially relationships. It is therefore important to treat pornography as a unique stimulus in reward, impulsivity, and addiction studies and to apply this accordingly in individual as well as relational treatment.

\section{References}

Agustín-Pavón, C., Martínez-Ricós, J., Martínez-García, F., \& Lanuza, E. (2008). Sex versus sweet: Opposite effects of opioid drugs on the reward of sucrose and sexual pheromones. Behavioral Neuroscience, 122, 416-425. doi:10.1037/0735-7044. 122.2.416

Allen, M., Emmers-Sommer, T. M., D'Alessio, D., Timmerman, L., Hanzal, A., \& Korus, J. (2007). The connection between the physiological and psychological reactions to sexually explicit materials: A literature summary using meta-analysis. Communication Monographs, 74, 541-560. doi:10.1080/03637 750701578648

Anthony, S. (2012, April 4). Just how big are porn sites? Extreme Tech. Retrieved on from http://www.extremetech.com/computing/ 123929-just-how-big-are-porn-sites

Arias-Carrión, O., Caraza-Santiago, X., Salgado-Licona, S., Salama M., Machado, S., Nardi, A.,... Murillo-Rodríguez, E. (2014). Orquestic regulation of neurotransmitters on rewardseeking behavior. International Archives of Medicine, 7, 29-44. doi:10.1186/1755-7682-7-29

Arias-Carrión, O., Stamelou, M., Murillo-Rodríguez, E., MenéndezGonzález, M., \& Pöppel, E. (2010). Dopaminergic reward system: A short integrative review. International Archives of Medicine, 3, 24. doi:10.1186/1755-7682-3-24

Bechara, A. (2005). Decision making, impulse control, and loss of willpower to resist drugs: A neurocognitive perspective. Nature Neuroscience, 8, 1458-1463. doi:10.1038/nn1584

Bickel, W. K., Jones, B. A., Landes, R. D., Christensen, D. R., Jackson, L., \& Mancino, M. (2010). Hypothetical intertemporal choice and real economic behavior: Delay discounting predicts voucher redemptions during contingency-management procedures. Experimental and Clinical Psychopharmacology, 18, 546-552. doi: $10.1037 / \mathrm{a} 0021739$

Bickel, W. K., Miller, M. L., Yi, R., Kowal, B. P., Lindquist, D. M., \& Pitcock, J. A. (2007). Behavioral and neuroeconomics of drug addiction: Competing neural systems and temporal discounting processes. Drug and Alcohol Dependence, 90, S85-S91. doi:10.1016/j.drugalcdep.2006.09.016

Boies, S. C. (2002). University students' uses of and reactions to online sexual information and entertainment: Links to online and offline sexual behaviour. Canadian Journal of Human Sexuality, $11,77-89$.

Braithwaite, S. R., Coulson, G., Keddington, K., \& Fincham, F. D. (2015). The influence of pornography on sexual scripts and hooking up among emerging adults in college. Archives of Sexual Behavior, 44, 111-123. doi:10.1007/s10508-014-0351-x

Buzzell, T., Foss, D., \& Middleton, Z. (2006). Explaining use of online pornography: A test of self-control theory and opportunities for deviance. Journal of Criminal Justice and Popular Culture, 13, 96-116.

Caplin, A., \& Dean, M. (2008). Dopamine, reward prediction error, and economics. Quarterly Journal of Economics, 123, 663-701. doi:10.1162/qjec.2008.123.2.663

Carpenter, D., Janssen, E., Graham, C., Vorst, H., \& Wicherts, J. (2008). Women's scores on the Sexual Inhibition/Sexual Excitation Scales (SIS/SES): Gender similarities and differences. Journal of Sex Research, 45, 36-48. doi:10.1080/00224490701808076 
Carroll, J. S., Padilla-Walker, L. M., Nelson, L. J., Olson, C. D., McNamara Barry, C., \& Madsen, S. D. (2008). Generation XXX: Pornography acceptance and use among emerging adults. Journal of Adolescent Research, 23, 6-30. doi:10.1177/0743558407306348

Cetin, T., Freudenberg, F., Füchtemeier, M., \& Koch, M. (2004). Dopamine in the orbitofrontal cortex regulates operant responding under a progressive ratio of reinforcement in rats. Neuroscience letters, 370, 114-117. doi:10.1016/j.neulet.2004.08.002

Chen, B. T., Bowers, M. S., Martin, M., Hopf, F. W., Guillory, A. M., Carelli, R. M.,... Bonci, A. (2008). Cocaine but not natural reward self-administration nor passive cocaine infusion produces persistent LTP in the VTA. Neuron, 59, 288-297. doi:10.1016/ j.neuron.2008.05.024

Chesson, H. W., Leichliter, J. S., Zimet, G. D., Rosenthal, S. L., Bernstein, D. I., \& Fife, K. H. (2006). Discount rates and risky sexual behaviors among teenagers and young adults. Journal of Risk and Uncertainty, 32, 217-230. doi:10.1007/s11166-006-9520-1

Colombo, M. (2014). Deep and beautiful: The reward prediction error hypothesis of dopamine. Studies in History and Philosophy of Science, Part C: Studies in History and Philosophy of Biological and Biomedical Sciences, 45, 57-67. doi:10.1016/j.shpsc.2013. 10.006

Cooper, A., Delmonico, D. L., \& Burg, R. (2000). Cybersex users, abusers, and compulsives: New findings and implications. Sexual Addiction and Compulsivity, 7, 5-29. doi:10.1080/10720160008 400205

Cooper, A., \& Griffin-Shelley, E. (2002). Introduction: The Internet: The next sexual revolution. In A. Cooper (Ed.), Sex and the Internet: A guidebook for clinicians (pp. 1-15). New York, NY: Brunner \& Routledge.

Crean, J. P., de Wit, H., \& Richards, J. B. (2000). Reward discounting as a measure of impulsive behavior in a psychiatric outpatient population. Experimental and Clinical Psychopharmacology, 8, 155-162. doi:10.1037/1064-1297.8.2.155

Davis, C., Patte, K., Curtis, C., \& Reid, C. (2010). Immediate pleasures and future consequences. A neuropsychological study of binge eating and obesity. Appetite, 54, 208-213. doi:10.1016/j.appet. 2009.11.002

Dewsbury, D. A. (1981). Effects of novelty of copulatory behavior: The Coolidge effect and related phenomena. Psychological Bulletin, 89, 464-482. doi:10.1037/0033-2909.89.3.464

Dixon, M. R., Jacobs, E. A., \& Sanders, S. (2006). Contextual control of delay discounting by pathological gamblers. Journal of Applied Behavior Analysis, 39, 413-422. doi:10.1901/jaba.2006.173-05

Doremus-Fitzwater, T. L., Varlinskaya, E. I., \& Spear, L. P. (2010). Motivational systems in adolescence: Possible implications for age differences in substance abuse and other risk-taking behaviors. Brain and Cognition, 72, 114-123. doi:10.1016/j.bandc.2009.08.008

Fawcett, T. W., McNamara, J. M., \& Houston, A. I. (2012). When is it adaptive to be patient? A general framework for evaluating delayed rewards. Behavioural Processes, 89, 128-136. doi:10.1016/ j.beproc.2011.08.015

Garcia, J. R., MacKillop, J., Aller, E. L., Merriwether, A. M., Sloan Wilson, D., \& Koji Lum, J. (2010). Associations between dopamine D4 receptor gene variation with both infidelity and sexual promiscuity. PLOS One, 5, 1-6. doi:10.1371/journal. pone. 0014162

Green, L., Myerson, J., \& Ostaszewski, P. (1999). Amount of reward has opposite effects on the discounting of delayed and probabilistic outcomes. Journal of Experimental Psychology: Learning, Memory, and Cognition, 25, 418-427. doi:10.1037/ 0278-7393.25.2.418

Hayaki, J., Anderson, B., \& Stein, M. (2006). Sexual risk behaviors among substance users: Relationship to impulsivity. Psychology of Addictive Behaviors, 20, 328-332. doi:10.1037/0893-164X.20.3.328

Hilton, D. L. (2013). Pornography addiction-A supranormal stimulus considered in the context of neuroplasticity. Socioaffective Neuroscience and Psychology, 3, 20767. doi:10.3402/snp.v3i0.20767
Hong, S.-B., Kim, J.-W., Choi, E.-J., Kim, H.-H., Suh, J.-E., Kim, C.-D.,... Yi, S.-H. (2013). Reduced orbitofrontal cortical thickness in male adolescents with Internet addiction. Behavioral and Brain Functions, 9, 1-5. doi:10.1186/1744-9081-9-11

Howard, A. C. (2014). Probability discounting of the quality of sexual relationships (Unpublished master's thesis). Southern Illinois University-Carbondale, Carbondale, IL.

Hoyle, R. H., Fejfar, M. C., \& Miller, J. D. (2000). Personality and sexual risk taking: A quantitative review. Journal of Personality, 68, 1203-1231. doi:10.1111/1467-6494.00132

Janssen, E., \& Bancroft, J. (2007). The dual control model: The role of sexual inhibition and excitation in sexual arousal and behavior. In E. Janssen (Ed.), The psychophysiology of sex (pp. 197-222). Bloomington: Indiana University Press.

Janssen, E., Vorst, H., Finn, P., \& Bancroft, J. (2002). The Sexual Inhibition (SIS) and Sexual Excitation (SES) Scales: II. Predicting psychophysiological response patterns. Journal of Sex Research, 39, 127-132. doi:10.1080/00224490209552131

Jentsch, J. D., Ashenhurst, J. R., Cervantes, M. C., Groman, S. M., James, A. S., \& Pennington, Z. T. (2014). Dissecting impulsivity and its relationships to drug addictions. Annals of the New York Academy of Sciences, 1327, 1-26. doi:10.1111/nyas.12388

Jentsch, J. D., \& Taylor, J. R. (1999). Impulsivity resulting from frontostriatal dysfunction in drug abuse: Implications for the control of behavior by reward-related stimuli. Psychopharmacology, 146, 373-390. doi:10.1007/PL00005483

Johnson, M. W., \& Bruner, N. R. (2012). The sexual discounting task: HIV risk behavior and the discounting of delayed sexual rewards in cocaine dependence. Drug and Alcohol Dependence, 123, 15-21. doi:10.1016/j.drugalcdep.2011.09.032

Kaplan, P. S. (2004). Adolescence. Boston, MA: Houghton Mifflin.

Kirby, K. N., \& Maraković, N. N. (1996). Delay-discounting probabilistic rewards: Rates decrease as amounts increase. Psychonomic Bulletin and Review, 3, 100-104. doi:10.3758/BF03210748

Kleitz-Nelson, H. K., Dominguez, J. M., Cornil, C. A., \& Ball, G. F. (2010). Is sexual motivational state linked to dopamine release in the medial preoptic area? Behavioral Neuroscience, 124, 300-304. doi:10.1037/a0018767

Koffarnus, M. N., Jarmolowicz, D. P., Mueller, E. T., \& Bickel, W. K. (2013). Changing delay discounting in the light of the competing neurobehavioral decision systems theory: A review. Journal of the Experimental Analysis of Behavior, 99, 32-57. doi:10.1002/jeab.2

Koukounas, E., \& McCabe, M. P. (2001). Sexual and emotional variables influencing sexual response to erotica: A psychophysiological investigation. Archives of Sexual Behavior, 30, 393-408. doi:10.1023/A:1010261315767

Krebs, R. M., Heipertz, D., Schuetze, H., \& Duzel, E. (2011). Novelty increases the mesolimbic functional connectivity of the substantia nigra/ventral tegmental area (SN/VTA) during reward anticipation: Evidence from high-resolution fMRI. Neuroimage, 58, 647-655. doi:10.1016/j.neuroimage.2011.06.038

Lambert, N. M., Negash, S., Stillman, T. F., Olmstead, S. B., \& Fincham, F. D. (2012). A love that doesn't last: Pornography consumption and weakened commitment to one's romantic partner. Journal of Social and Clinical Psychology, 31, 410-438. doi:10.1521/jscp.2012.31.4.410

Lawyer, S. R. (2008). Probability and delay discounting of erotic stimuli. Behavioural Processes, 79, 36-42. doi:10.1016/j.beproc. 2008.04.009

Lawyer, S. R., Williams, S. A., Prihodova, T., Rollins, J. D., \& Lester, A. C. (2010). Probability and delay discounting of hypothetical sexual outcomes. Behavioural Processes, 84, 687-692. doi: 10.1016/j.beproc.2010.04.002

Lungu, F., \& Puscasu, A. (2013). What is neuroeconomics? II. Experimental neuroeconomics and game theory. Review of Management and Economic Engineering, 12, 17-24.

MacKillop, J. (2013). Integrating behavioral economics and behavioral genetics: Delayed reward discounting as an endophenotype 


\section{NEGASH, SHEPPARD, LAMBERT, AND FINCHAM}

for addictive disorders. Journal of the Experimental Analysis of Behavior, 99, 14-31. doi:10.1002/jeab.4

Malesza, M., \& Ostaszewski, P. (2013). Relations between Cloninger's dimensions of temperament and steepness of delay and effort discounting of monetary rewards. Psychological Reports, 112, 694-705. doi:10.2466/09.14.PR0.112.3.694-705

Mischel, W., \& Underwood, B. (1974). Instrumental ideation in delay of gratification. Child Development, 45, 1083-1088. doi:10.1111/ j.1467-8624.1974.tb00708.x

Oliveira, C., Laja, P., Carvalho, J., Quinta Gomes, A., Vilarinho, S., Janssen, E., \& Nobre, P. J. (2014). Predictors of men's sexual response to erotic film stimuli: The role of affect and selfreported thoughts. Journal of Sexual Medicine, 11, 2701-2708. doi: $10.1111 /$ jsm. 12650

O'Malley, K., Davies, A., \& Cline, T. W. (2010). Do psychological cues alter our discount function? North American Journal of Psychology, 12, 469-480.

Philaretou, A., Mahfouz, A., \& Allen, K. (2005). Use of Internet pornography and men's well-being. International Journal of Men's Health, 4, 149-169. doi:10.3149/jmh.0402.149

Phillips, A. G., Vacca, G., \& Ahn, S. (2008). A top-down perspective on dopamine, motivation, and memory. Pharmacology, Biochemistry, and Behavior, 90, 236-249. doi:10.1016/j.pbb.2007.10.014

Porn sites get more visitors each month than Netflix, Amazon, \& Twitter combined. (2013, May 4). Huffington Post. Retrieved from http://www.huffingtonpost.com/2013/05/03/internet-porn-stats_ n_3187682.html

Quinn, J. F., \& Forsyth, C. J. (2005). Describing sexual behavior in the era of the Internet: A typology for empirical research. Deviant Behavior, 26, 191-207. doi:10.1080/01639620590888285

Rachlin, H., \& Green, L. (1972). Commitment, choice, and selfcontrol. Journal of the Experimental Analysis of Behavior, 17, 15-22. doi:10.1901/jeab.1972.17-15

Ramanathan, S., \& Menon, G. (2006). Time-varying effects of chronic hedonic goals on impulsive behavior. Journal of Marketing Research, 43, 628-641. doi:10.1509/jmkr.43.4.628

Romano, M., Osborne, L. A., Truzoli, R., \& Reed, P. (2013). Differential psychological impact of Internet exposure on Internet addicts. PLOS One, 8, 1-4. doi:10.1371/journal.pone.0055162

Romer, D., Duckworth, A. L., Sznitman, S., \& Park, S. (2010). Can adolescents learn self-control? Delay of discounting in the development of control over risk taking. Prevention Science, 11, 319-330. doi:10.1007/s11121-010-0171-8

Ropelato, J. (2007). Internet pornography statistics. Top Ten Reviews. Retrieved from http://internet-filter-review.toptenreviews.com/ internet-pornography-statistics.html

Saville, B. K., Gisbert, A., Kopp, J., \& Telesco, C. (2010). Internet addiction and delay discounting in college students. Psychological Record, 60, 273-286.

Schramm-Sapyta, N. L., Walker, Q. D., Caster, J. M., Levin, E. D., \& Kuhn, C. M. (2009). Are adolescents more vulnerable to drug addiction than adults? Evidence from animal models. Psychopharmacology, 206, 1-21. doi:10.1007/s00213-009-1585-5

Short, M. B., Black, L., Smith, A. H., Wetterneck, C. T., \& Wells, D. E. (2012). A review of Internet pornography use research: Methodology and content from the past 10 years. Cyberpsychology, Behavior, and Social Networking, 15, 13-23. doi:10.1089/cyber.2010.0477

Smits, R. R., Stein, J. S., Johnson, P. S., Odum, A. L., \& Madden, G. J. (2013). Test-retest reliability and construct validity of the experiential discounting task. Experimental and Clinical Psychopharmacology, 21, 155-163. doi:10.1037/a0031725

Stein, J. S., \& Madden, G. J. (2013). Delay discounting and drug abuse: Empirical, conceptual, and methodological considerations.
In J. MacKillop \& H. de Wit (Eds.), The Wiley-Blackwell handbook of addiction psychopharmacology (pp. 165-208). Chichester, West Sussex, UK: Wiley-Blackwell.

Steinberg, L., Graham, S., O'Brien, L., Woolard, J., Cauffman, E., \& Banich, M. (2009). Age differences in future orientation and delay discounting. Child Development, 80, 28-44. doi:10.1111/j.14678624.2008.01244.x

Tayler, S., Arantes, J., \& Grace, R. C. (2009). Temporal discounting for monetary and close relationship outcomes. Personal Relationships, 16, 385-400. doi:10.1111/j.1475-6811.2009.01229.x

Van den Bergh, B., Dewitte, S., \& Warlop, L. (2008). Bikinis instigate generalized impatience in intertemporal choice. Journal of Consumer Research, 35, 85-97. doi:10.1086/525505

Volkow, N. D., Wang, G.-J., Fowler, J. S., Tomasi, D., Telang, F., \& Baler, R. (2010). Addiction: Decreased reward sensitivity and increased expectation sensitivity conspire to overwhelm the brain's control circuit. Bioessays: News and Reviews in Molecular, Cellular, and Developmental Biology, 32, 748-755. doi:10.1002/ bies. 201000042

Watkins, L. E., Maldonado, R. C., \& DiLillo, D. (2014). Hazardous alcohol use and intimate partner aggression among dating couples: The role of impulse control difficulties. Aggressive Behavior, 4, 369-381. doi:10.1002/ab.21528

Wetterneck, C. T., Burgess, A. J., Short, M. B., Smith, A. H., \& Cervantes, M. E. (2012). The role of sexual compulsivity, impulsivity, and experiential avoidance in Internet pornography use. Psychological Record, 62, 3-18.

Wilson, G. (2014). Your brain on porn: Internet pornography and the emerging science of addiction. Kent, UK: Commonwealth.

Wilson, J. R., Kuehn, R. E., \& Beach, F. A. (1963). Modification in the sexual behavior of male rats produced by changing the stimulus female. Journal of Comparative and Physiological Psychology, 56, 636-644. doi:10.1037/h0042469

Wilson, M., \& Daly, M. (2004). Do pretty women inspire men to discount the future? Proceedings of the Royal Society B: Biological Sciences, 271, S177-S179. doi:10.1098/rsbl.2003.0134

Winstanley, C. A. (2010). The neural and neurochemical basis of delay discounting. In G. Madden \& W. Bickel (Eds.), Impulsivity: The behavioral and neurological science of discounting (pp. 95-121). Washington, DC: American Psychological Association.

Wise, R. A. (1980). The dopamine synapse and the notion of 'pleasure centers' in the brain. Trends in Neuroscience, 3, 91-95. doi:10.1016/0166-2236(80)90035-1

Wright, P. J. (2012). A longitudinal analysis of U.S. adults' pornography exposure. Journal of Media Psychology, 24, 67-79. doi:10.1027/ 1864-1105/a000063

Wright, P. J. (2013). U.S. males and pornography, 1973-2010: Consumption, predictors, correlates. Journal of Sex Research, 50, 60-71. doi:10.1080/00224499.2011.628132

Wright, P. J., \& Randall, A. K. (2012). Internet pornography exposure and risky sexual behavior among adult males in the United States. Computers in Human Behavior, 28, 1410-1416. doi:10.1016/ j.chb.2012.03.003

Wright, P. J., Tokunaga, R. S., \& Bae, S. (2014a). More than a dalliance? Pornography consumption and extramarital sex attitudes among married U.S. adults. Psychology of Popular Media Culture, 3, 97-109. doi:10.1037/ppm0000024

Wright, P. J., Tokunaga, R. S., \& Bae, S. (2014b). Pornography consumption and U.S. adults' attitudes toward gay individuals' civil liberties, moral judgments of homosexuality, and support for same-sex marriage: Mediating and moderating factors Communication Monographs, 81, 79-107. doi:10.1080/03637751. 2013.871048 